\title{
2D Geoelectric Imaging of the Uneme-Nekhua Fracture Zone
}

\author{
Muslim B. Aminu, Tunde M. Akande, and Olubukola A. Ishola \\ Department of Earth Sciences, Adekunle Ajasin University, Akungba-Akoko 342111, Nigeria \\ Correspondence should be addressed to Muslim B. Aminu; muslimaminu@gmail.com
}

Received 6 February 2014; Revised 31 March 2014; Accepted 12 May 2014; Published 4 June 2014

Academic Editor: Filippos Vallianatos

Copyright (C) 2014 Muslim B. Aminu et al. This is an open access article distributed under the Creative Commons Attribution License, which permits unrestricted use, distribution, and reproduction in any medium, provided the original work is properly cited.

\begin{abstract}
We have employed 2D geoelectric imaging to reveal the geometry and nature of a fracture zone in Uneme-Nekhua, southwestern Nigeria. The fracture zone is discernable from an outcropping rock scarp and appears to define the course of a seasonal stream. Data were acquired using the dipole-dipole survey array configuration with electrode separation of $6 \mathrm{~m}$ and a maximum dipole length of $60 \mathrm{~m}$. Three traverses with lengths varying between $72 \mathrm{~m}$ and $120 \mathrm{~m}$ were laid orthogonal to the course of the seasonal stream. 2D geoelectric images of the subsurface along the profiles imaged a north-south trending fracture zone. This fracture zone appears to consist of two vertical fractures with more intense definition downstream. The eastern fracture is buried by recent sediment, while the western fracture appears to have experienced more recent tectonic activity as it appears to penetrate through the near surface. Perhaps at some point, deformation ceased on the eastern fracture and further strain was transferred to the western fracture. The fracture zone generally defines the course of the north-south seasonal stream with the exception of the downstream end where the fracture appears to have died out entirely. Two associated basement trenches lying parallel to and east of the fracture zone are also imaged.
\end{abstract}

\section{Introduction}

During an annual student field work exercise in 2012, we noticed at one end of Uneme-Nekhua (Figure 1), a linear settlement in the northwestern region of Edo State, Nigeria, a rock escarpment which appeared to suggest relative displacement between rock masses on opposite sides of a perennial spring from which locals derived water (Figure 2). Further observations appeared to reveal that rock masses on either side of the spring were of the same lithology (specifically, highly banded grey gneiss) and that the spring was part of a narrow roughly north-south trending seasonal stream course dotted with thick vegetation compared with the rest of the immediate landscape. Further to the south, the stream path was broader (creating a low lying flood plain) and numerous rock boulders (some of massive quartz) could be seen. This suggests an intense degree of brecciation and or possibly multiple fracture paths. Further away from the stream path, on either side, topography is ridge like and locals have taken advantage of the eastern ridge to site their residences. We decided to attempt to confirm our initial observations and image the fracture zone and also determine its propagation geometry downstream. Here we present the result of a $2 \mathrm{D}$ geoelectric imaging of the Uneme-Nekhua fracture zone and its geometry.

The principles of electrical resistivity prospecting were developed in the earlier 1900s but became widely implemented from the 1970s onward. This was mainly due to the development of computers which could process and analyze the data [1]. The method involves injecting electrical current into the ground via two electrodes and measuring the resulting ground potential between the other two electrodes at predetermined locations (Figure 3 ). The electrical response of the earth was thus measured and the spatial configuration coupling between the current and potential electrode pairs is used to create a geoelectrical response of the subsurface $[2,3]$. The advent of multichannel recording systems and automated switching systems and the development of fast and robust computer based inversion schemes have led to rapid increases in the application of electrical resistivity imaging techniques $[1,3]$. Electrical resistivity techniques have been 


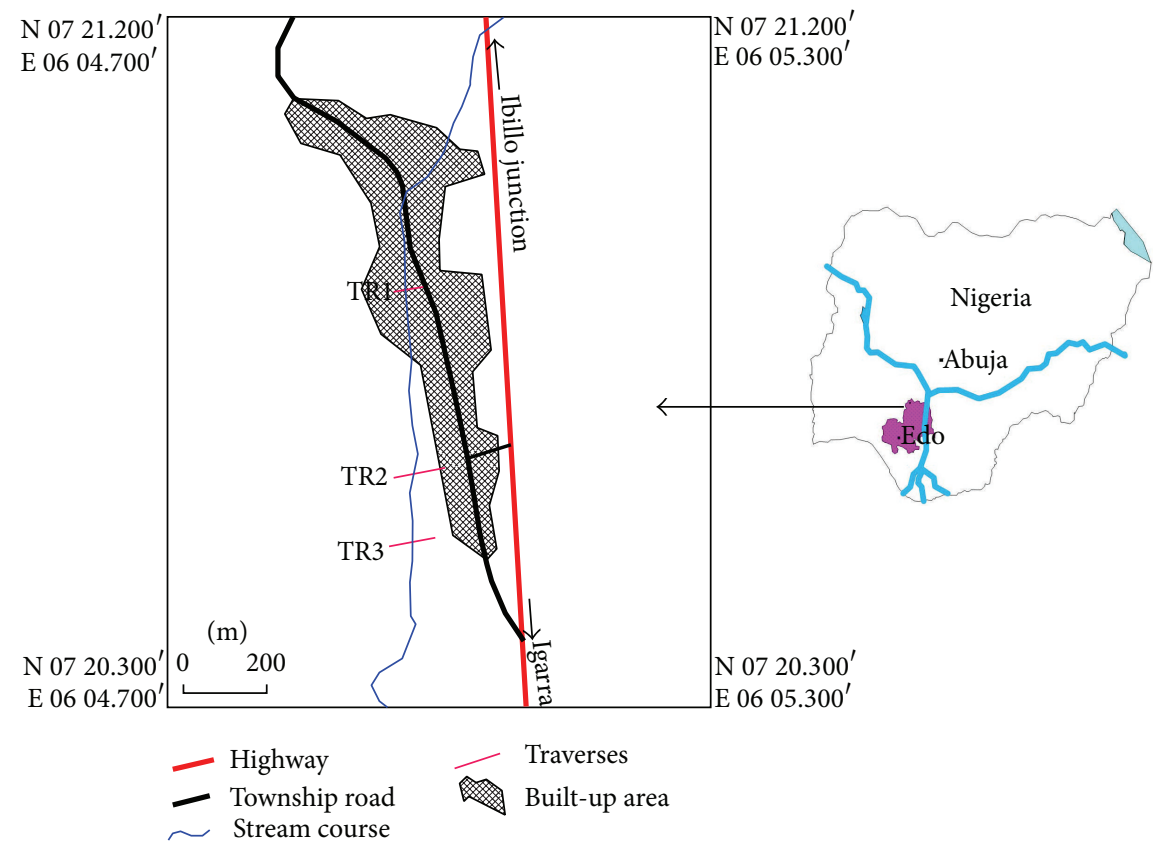

FIGURE 1: Composite map of study location. Uneme-Nekhua is an elongate settlement parallel to the Ibillo-Igarra highway. The built-up area generally takes advantage of a ridge structure, while the stream course follows in the adjacent valley west of the ridge.

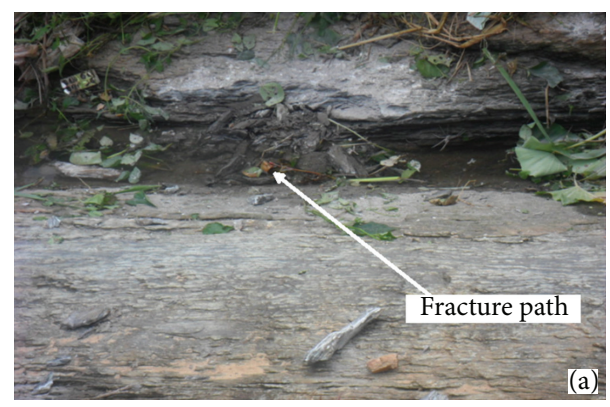

(a)

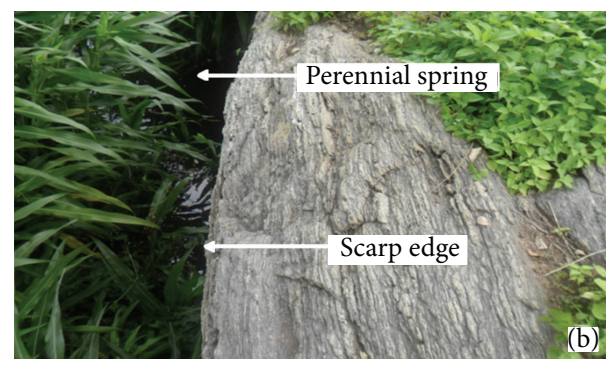

(b)

FIgURE 2: Surface manifestations of the Uneme-Nekhua fracture zone: (a) dry fracture/stream path before the onset of considerable rains and (b) rock scarp with perennial spring from which locals derive water in the dry season.

used in landfill boundary imaging and characterization $[4,5]$, in fault imaging [6-9], karst/cave imaging [10], agricultural study [11], and several other applications [1].

In Bufford et al., [8], magnetotelluric (MT) and electrical resistivity tomography (ERT) were used to image the

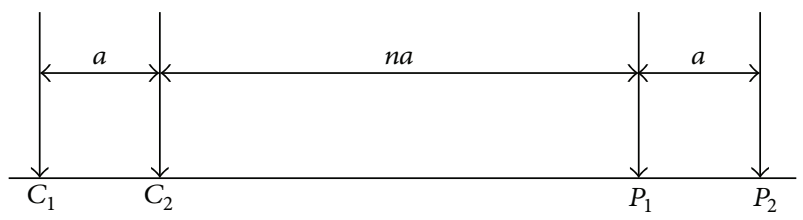

$\rho_{a}=K \frac{\Delta V}{I}$

$\rho_{a}=n \pi a(n+1)(n+2)$

$C_{1}$ and $C_{2}=$ current source and sink electrodes

$P_{1}$ and $P_{2}=$ potential electrodes

FIGURE 3: Typical dipole-dipole electrode configuration for the electrical resistivity method (Redrawn after Loke, 2000 [3]).

geometry and nature of fault activity of the Okavango Rift Zone (ORZ) in Botswana in the Southwestern Branch of the East African Rift System. The Rift Zone was imaged as a low resistivity pathway which channeled both surface water and groundwater from the Okavango Delta and recirculated it through the lacustrine and fluviodeltaic sediments filling the basin. El-Qady et al., [10], employed ground penetrating radar and electrical resistivity imaging to reveal the subsurface structure of a karst cave with known surface expressions, over a proposed site for low income residential apartments in the eastern parts of greater Cairo. They reported the detection of previously unknown extensions of the cave system, zones of marl, and multiple vertical fractures in limestones. Ololade et al., [11], in an integrated survey, employed electrical resistivity imaging to reveal the subsurface geology of an agricultural region where recent spirited efforts to cultivate cocoa showed poor results after initial bright prospects. Their 
study revealed that initial luxuriant growth of cultivated cocoa seedlings was due to rich but thin topsoil which arose from foliage decomposition. As the seedlings grew, their roots came in contact with the highly porous and leached sands underlying the topsoil and consequently, growth declined.

\section{Site of Investigation}

Uneme-Nekhua is located between longitudes $0605.700^{\prime}$ and $0605.300^{\prime}$ and latitudes $0720.300^{\prime}$ and $0721.200^{\prime}$ in the northwestern region of Edo State, Nigeria (Figure 1). The area is underlain by the rocks of the migmatite-gneiss complex (as described in Rahaman, [12]) of the basement rocks of the southwestern Nigeria. Specifically, the rocks are grey gneisses with high rising granitic intrusions. There is also evidence of a quartzite ridge, possibly underlying part of the settlement and informing its linearity. The settlement runs in the north-northwest direction, roughly parallel to the IbilloAuchi highway except at its northern end where it turns northwestwards and then north (Figure 1). The northern limit of the settlement is bisected by a north-south running seasonal stream. The rest of the stream course southwards runs to the west and nearly parallel to the settlement. In the dry season, the stream course is waterless except for a perennial spring located beneath a rock escarpment towards the northern end of the settlement. The southern course of the stream is wider and gentler compared to the northern end. This wider/gentler course has an associated flood plain and has apparently allowed the stream to develop a high degree of sinuosity towards its southerly end. The stream can be seen cutting its path through relatively thick $(>2 \mathrm{~m}$ ) clayey sand overburden in this southern end of the area. The basement complex of southwestern Nigeria is known to be characterized by thin regolith development [13], however, a series of tectonic events have created numerous minor faults and fractures, and highly jointed rocks [12]. These structures in several cases serve as conduits for the flow of groundwater and may serve as the only source of water to locals during the dry season [14].

\section{Methodology}

Electrical resistivity data were collected using the ABEM 1000 Terrameter unit, manufactured by ABEM Instrument $A B$ (Sweden). The unit used for this survey had 4 steel electrodes and 4 cables reels ( 2 each of $250 \mathrm{~m}$ and $750 \mathrm{~m}$ maximum lengths). The electrical resistivity data were collected along three roughly East-West traverses across the course of the seasonal stream. The traverses are designated in order from north to south TR1, TR2, and TR3 (Figure 1). The dipoledipole survey array configuration was employed on all three traverses (Figure 3). The dipole-dipole array configuration was preferred due to the following reasons: (a) the fact that the dipole-dipole array configuration is very sensitive to lateral variations in the geoelectric signatures of the subsurface and is thus highly suitable for mapping vertical structures such as faults/fractures and dyke [3], (b) the low EM coupling of the dipole-dipole array configuration relative to other commonly used arrays [15], and (c) relative ease of use in the study area compared to the pole-dipole array which requires a remote electrode theoretically at infinite distance. Electrode separation was maintained at $6 \mathrm{~m}$ on all traverses and the maximum dipole separation was $60 \mathrm{~m}$. Total traverse lengths were $72 \mathrm{~m}, 120 \mathrm{~m}$, and $84 \mathrm{~m}$ along TR1, TR2, and TR3, respectively. Traverses were laid orthogonal to the suspected fracture as defined by the course of the associated seasonal stream. TR3 was the longest as its location indicated a broadening and flattening out of the stream course. The location of TR1 dips slightly from both ends towards the center (with the center being roughly $0.45 \mathrm{~m}$ lower than either end of the traverse), while the locations of TR2 and TR3 were totally flat.

The field resistivity data were processed using the DIPROfWIN 4.01 software developed by Dr. Jung Ho Kim of the Korea Institute of Mining and Geology (KIGAM). DIPROfWIN is a fully automated two and half-dimensional (2.5D) inversion routine based on a finite difference modeling (FDM) or finite element modeling (FEM) approximations to the calculation of model responses. The software inverts the data using the smoothness-constrained least-squares inversion algorithm to achieve stable results. The program uses the active constraint balancing (ACB) method which accounts for the use of variable Lagrangian multiplier at each of the parameterized blocks of the model during the inversion process to enhance both resolution and stability [16]. The FEM inversion method was used to process data for this survey.

The inversion algorithm first computes an initial model of subsurface resistivity distribution using the calculated apparent resistivity values and generates a response resistivity field based on the initial model, and then it computes and iteratively minimizes the error between the synthetic and observed resistivity fields until a reasonable fit is achieved. Once the misfit is less than 5\%, the iteration is stopped and the result is output. The results displayed in the output window include the observed field pseudosection, the computed theoretical data pseudosection, and the inverted subsurface $2 \mathrm{D}$ resistivity structure. The variation topography along TR1 was not considered significant as to be used in the modeling process.

\section{Results}

Electrical resistivity data were collected along 3 traverses. Figure 4 is a composite plot of the field data pseudosection, the computed theoretical data pseudosection, and the inverted 2D resistivity structure along TR1. The TR1 resistivity profile can be divided into three response patterns: (1) a very thin uppermost lateral low resistivity response layer with resistivity in the range of $11-90 \mathrm{ohm}-\mathrm{m}$. This response pattern is rarely more than $3 \mathrm{~m}$ thick along the profile. It vanishes entirely between $43 \mathrm{~m}$ and $52 \mathrm{~m}$ along the profile. We interpret this layer as the thin soil cover which lies upon the basement rocks at the study site. The basement rocks of southwestern Nigeria are known to be covered by a thin regolith formed usually as a 


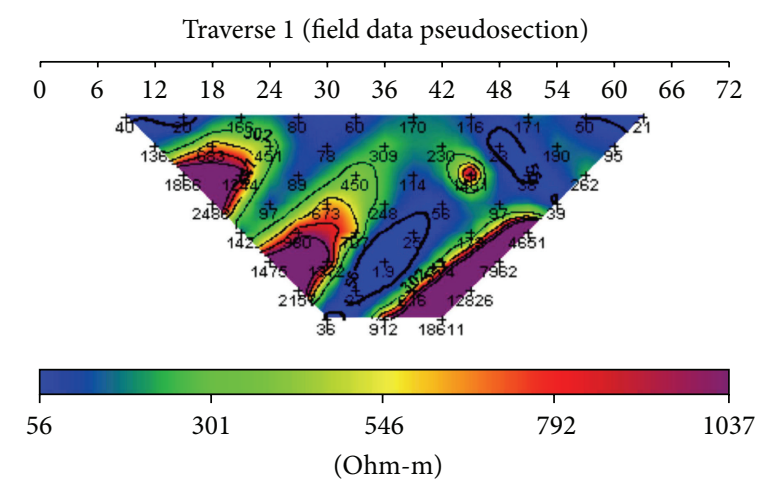

(a)

Traverse 1 (theortical data pseudosection)

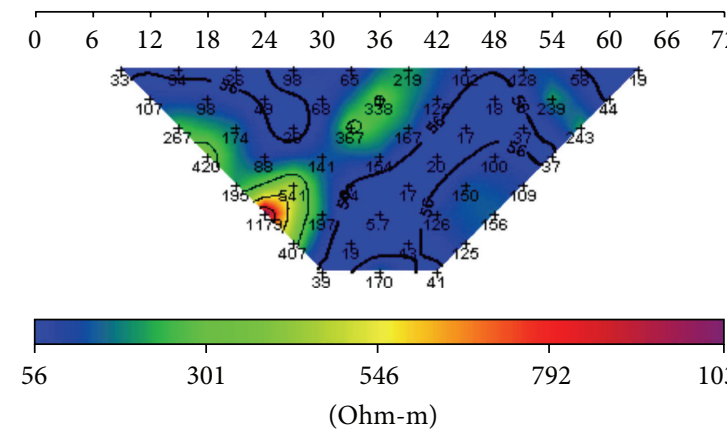

(b)

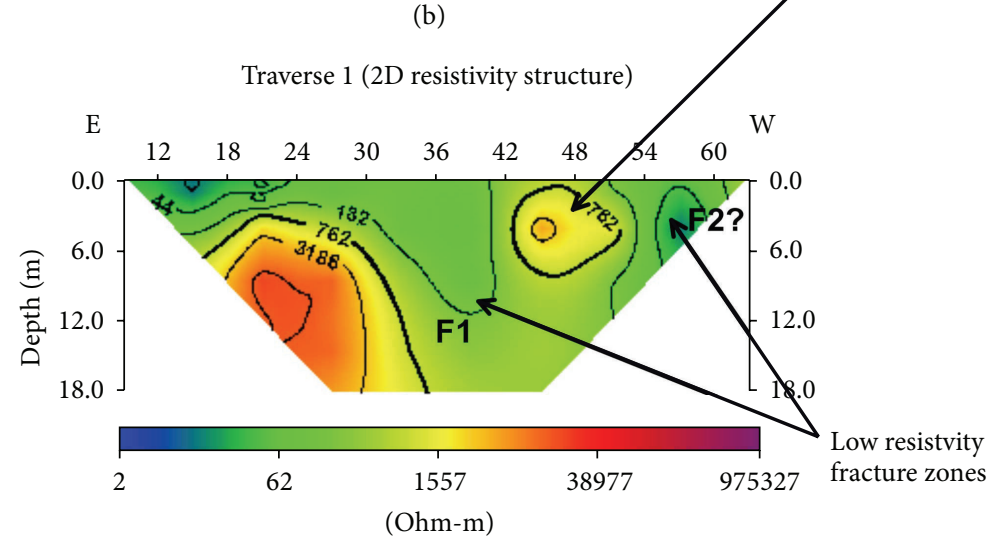

(c)

FIGURE 4: Composite plot of the results of 2D resistivity inversion along TR1: (a) observed resistivity data pseudosection, (b) computed resistivity distribution, and (c) inverted resistivity structure. Low resistivity structures F1 and F2 (interpreted as fracture paths) are separated by a high resistivity structure which outcrops as crystalline rock a little north of the traverse.

result of in-situ weathering of the basement rocks $[13,14]$; (2) an extensive high resistivity response pattern with resistivity values generally greater than $700 \mathrm{ohm}-\mathrm{m}$. This response is separated into western and eastern segments by a near vertical lower resistivity response pattern in the middle of the profile. The western segment of this high resistivity response is not overlain by the low resistivity soil cover described above and extends from the ground surface to a depth of about $10 \mathrm{~m}$. The eastern segment extends from a depth of about $4 \mathrm{~m}$ till beyond the maximum imaged depth of the profile of $18 \mathrm{~m}$. We interpret this response patterns as representing the unweathered basement rock at the site. The western segment virtually outcrops along the profile between $43 \mathrm{~m}$ and $52 \mathrm{~m}$ and can be observed visually outcropping a few meters north of the traverse. The low resistivity response pattern separating the two segments represents a breach in the consistency of the basement rock along the profile and a lack of continuity. The western segment also appears surrounded further west by lower resistivity responses. This would imply that the western segment of this high resistivity response is a huge boulder unit totally detached from the downwardly continuous basement rock 
represented in part by the eastern segment; and (3) two near vertical response patterns: one of very low resistivity in the range $30-60 \mathrm{ohm}-\mathrm{m}$ and the second of moderate resistivity in the range of $60-230 \mathrm{ohm}-\mathrm{m}$. These signatures separate the two high resistivity segments mentioned above which we interpreted as the fresh basement rocks in the area. The western pattern extends from a depth of $1.5 \mathrm{~m}$ from ground surface downwards, while the second pattern extends all the way to the surface and appears of dip westwards at roughly $85^{\circ}$ to the west. The full depth extent of these response patterns is not imaged as they transcend the maximum imaged depth of $18 \mathrm{~m}$ along the profile. These patterns serve as discontinuities in the high resistivity basement rock pattern along the profile. We therefore interpret these signatures as the subsurface expressions of multiple fractures: the first (western) is a fracture buried by thicker topsoil and the eastern pattern is considered as the fracture we perceived along the course of the seasonal stream, specifically at the location of the perennial spring. The low resistivity responses of these fracture paths would be due to increased porosity resulting from fracturing of the basement rocks along the traces of these signatures and possible subterranean fluid migration through them. Higher porosity and fluid content are known to considerably lower rock resistivity $[3,8,17]$ and such a situation might create "fault zones conductors" [18]. The western fracture has lower resistivity response compared with the eastern fracture and possibly suggests greater fluid conductivity at depth. Its lower resistivity signature possibly stems from greater porosity and indicates that it channels a higher fluid volume in the subsurface. TR1 could not be extended westwards to fully image this western fracture due to building obstructions.

Figure 5 is the inverted $2 \mathrm{D}$ resistivity structure and inferred geologic model along TR2. This profile similarly to TR1 can be divided into three distinct resistivity response patterns. (1) The first resistivity response pattern is a thin uppermost lateral low resistivity response layer with resistivity in the range of $30-70 \mathrm{ohm}-\mathrm{m}$. This response pattern extends from the ground surface to an average depth of between 3 and $5 \mathrm{~m}$ along the profile. This pattern extends laterally all through the profile length except between $72 \mathrm{~m}$ and $90 \mathrm{~m}$ where it is interrupted by pockets of very low resistivity responses $(<18 \mathrm{ohm}-\mathrm{m})$. We again interpret this layer as the thin soil cover which lies upon the basement rocks at the study site. Along this profile (TR2), the regolith appears relatively better developed as it attains an average thickness of $3-5 \mathrm{~m}$. (2) The second resistivity response pattern is an extensive high resistivity response pattern with resistivity values generally greater than $1000 \mathrm{ohm}-\mathrm{m}$. This response again (as seen along TR1) is separated into western and eastern segments by a vertical and more extensive lower resistivity response pattern. The western segment of this high resistivity response is only partly imaged along the profile. It extends from a depth of about $6 \mathrm{~m}$ below the ground surface downwards. The eastern edge of this segment appears near vertical. The eastern segment extends laterally from the eastern limit of the profile to about $70 \mathrm{~m}$ along the profile. Generally this segment extends vertically from a depth between 3 and $7 \mathrm{~m}$ below the ground surface downwards till beyond the maximum imaged depth of the profile of $18 \mathrm{~m}$. This segment has a highly undulating surface, forming two trenches up to $4 \mathrm{~m}$ deep measuring from the shallowest edge of the high resistivity response. These trenches are indicative of deep weathering and development of considerably thicker regolith compared to the location of traverse 1 . There is no discernable indication that the undulation of the surface of this segment is structurally induced. We again interpret this response patterns as representing the unweathered basement rock at the site. The low resistivity breach in the consistency of the basement rock along this profile is vertical and laterally more extensive than on TR1. Its distance spans from $72 \mathrm{~m}$ to $90 \mathrm{~m}$ along the profile; (3) a vertical and extensive low resistivity response pattern. This low resistivity zone coincides with the broadened course of the stream where we initially observed numerous massive rock boulders. This pattern includes two very low resistivity vertical structures, with resistivity values generally lower than $18 \mathrm{ohm}-\mathrm{m}$. These two structures are separated by a comparatively higher resistivity response, which is also vertical, with resistivity values in the range of $60-100 \mathrm{ohm}-\mathrm{m}$. The western structure extends from the ground surface where it punctuates the lateral low resistivity cover (described above) down to the imaged depth of the profile $(18 \mathrm{~m})$. The second structure does not penetrate to the ground surface but extends from a depth of roughly $5 \mathrm{~m}$ downwards. We interpret these signatures as representing the subsurface expressions of a zone of multiple fracturing. Apparently, there are at least two fractures involved. These are indicated in the very low vertical resistivity structures. The structures are possibly separated by a vertical slab of more competent rock represented by the comparatively higher vertical resistivity response. It is plausible that the more westerly fracture is of more recent origin. This appears to have allowed it to penetrate all the way to the near-surface, thereby interrupting the more recent sediments along the stream course, while the more easterly fracture appears to be covered by recent sediments and does not penetrate to the ground surface. The resistivity signature of the more easterly structure is much lower than that imaged along TR1 (<18 ohm-m compared to a range of $60-230 \mathrm{ohm}-\mathrm{m})$. This is most likely due to the apparent more intense degree of fracturing (resulting in brecciation along the profile). This would have created more open fractures and increased porosity and would possibly allow greater fluid saturation and migration through it. All of these factors combined would engender much lower resistivities.

Figure 6 is the inverted $2 \mathrm{D}$ resistivity structure along TR3. This profile can also be divided into three distinct resistivity response patterns. However, the resistivity patterns are not exactly the same with other profiles. (1) The first resistivity response pattern is a thin uppermost lateral low resistivity response layer with resistivity in the range of 45$120 \mathrm{ohm}-\mathrm{m}$. This pattern extends laterally all through the profile length. Vertically, it extends from the ground surface to an average depth of just over $3 \mathrm{~m}$. As for distance from $15 \mathrm{~m}$ to $28 \mathrm{~m}$, this signature deepens and reaches a maximum depth of about $6 \mathrm{~m}$, thereby forming a deep weathering trench. We again interpret this layer as the thin soil cover in the study area. Along this profile, it does not directly 


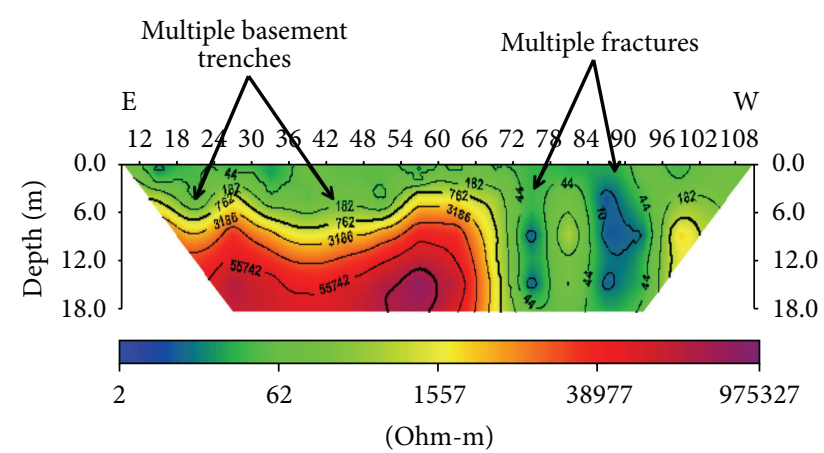

(a)

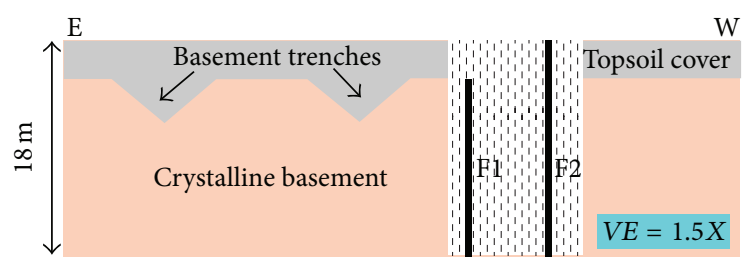

(b)

FIGURE 5: Composite profile along TR2 indicating the locations of vertically dipping multiple low resistivity fracture paths towards the western end of the profile and multiple depressions (trenches) within the adjacent high resistivity crystalline basement to the East. (a) Inverted 2D resistivity structure along TR2, (b) conceptual geologic cross-section along traverse 2. Deep seep of surface waters within the fractures leads to very low resistivity responses. Alternately, the entire grey shaded zone could represent a continuous zone where brecciation was heterogeneous. Above the multiple fractures a broad flood plain where the stream course is less entrenched has developed.

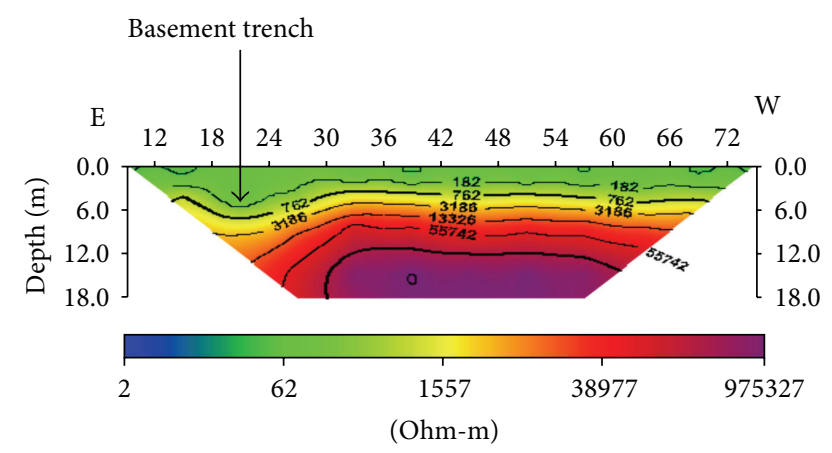

FIGURE 6: Inverted 2D resistivity structure along TR3. The fracture paths appear to have died out completely at the downstream end, but a basement trench in the eastern limit of the traverse is imaged.

overlie the high resistivity pattern we earlier interpreted as the unweathered basement, but it lies upon an intermediate resistivity signature. (2) The second resistivity response pattern is a laterally extensive intermediate resistivity response pattern with resistivity values generally in the range of 400$1500 \mathrm{ohm}-\mathrm{m}$. This response pattern extends from an average depth of just over $3 \mathrm{~m}$ below the ground surface to about $7 \mathrm{~m}$. In the easterly limits of the profile, from about $15 \mathrm{~m}$ to $28 \mathrm{~m}$, the pattern extends further downwards to a maximum depth of $11 \mathrm{~m}$, following the trench shape of the overlying low resistivity pattern. We interpret this response patterns as representing the partly weathered basement rock at the site. This layer response is absent from TR1 and TR2. (3) The third resistivity response pattern is an extensive high resistivity response pattern with resistivity values generally greater than $2000 \mathrm{ohm}-\mathrm{m}$. This response extends from an average depth of $7 \mathrm{~m}$ to downwards. It is generally flat at its contact with the overlying intermediate resistivity pattern with the exception of the eastern limits of the profile where it is encountered at a depth of $11 \mathrm{~m}$ and forms a trench. In comparison to profiles TR1 and TR2, where the boundaries between the unweathered basement and the topsoil are sharp, the intermediate pattern along this profile (TR3) appears to represent a more gradational boundary between the unweathered basement rock and the overlying topsoil. We again interpret this pattern as representing the unweathered basement rock in the study area. Along this profile, this high resistivity pattern is continuous and the vertical low resistivity patterns seen on profiles TR1 and TR2 which segments it into western and eastern sections is absent. We conclude that the stream course along this profile is not structurally controlled. On visual inspection of the site, the stream is seen to cut a relatively deep groove $(\sim 1.5 \mathrm{~m})$ into the top soil cover. The stream course on other profiles lacks this deep groove. The stream course in this part of the study area is also characterized by the development of higher sinuosity, further indicating that the course is not structurally controlled in this region.

\section{Discussion}

The recent work of Moisidi et al. [9] indicates that faults zones either with or without surface expressions can be imaged using electrical resistivity tomographic surveys because they serve to conduct water in the subsurface. They could show up as vertical higher resistivity paths within very low resistivity formations saturated with saline waters in which case they serve to channel fresh groundwater at depth and act as flow barriers. Otherwise, they could mark the boundaries between formations of different lithologies. Figure 7 is a composite fences diagram showing the $2 \mathrm{D}$ geoelectric sections discussed earlier in this paper. The geoelectric profile TR1 suggests that the Uneme-Nekhua fracture system consists of two fractures "F1" and "F2." On this traverse, "F1" appears to dip westward at a high angle $\left(\sim 85^{\circ}\right)$ and separates the fresh unweathered basement rocks into western and eastern segments. "F2" is not fully imaged but appears vertical. The profile possibly suggests some throw along the "F1" fracture. Downstream at TR2, the multiple fracture system is imaged as a broad lower resistivity zone with two distinct vertical $\left(90^{\circ}\right)$ fractures 


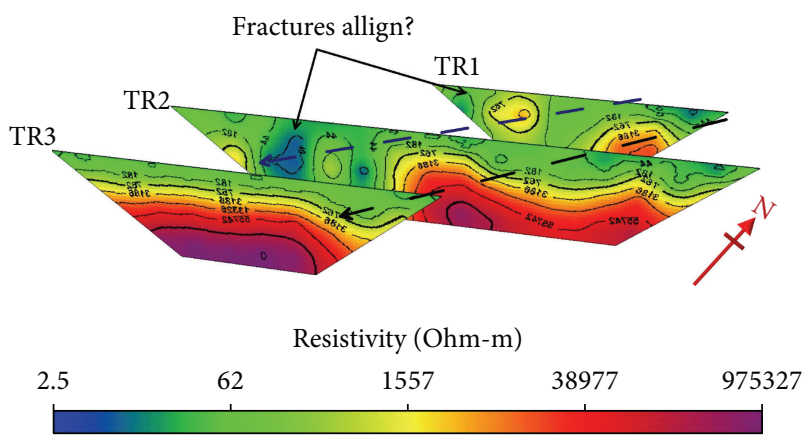

FIGURE 7: 3D composite fence plot from inverted 2D resistivity structures of the Uneme-Nekhua fracture zone (refer to Figure 1 for actual spatial distances between traverses). Fracture locations along TR1 and TR2 and basement trenches on all traverses are seen to align. The fractures likely are continuous in the subsurface with the exception of the location of TR3 downstream. Blue and black dashed arrow headed lines indicate aligned fracture and basement trench trends. These are essential conduits for groundwater migration within the area.

separated by a vertical slab of more cohesive rock. These fractures appear to have broadened the stream path and created the associated low-lying flood plain which can be observed in the dry season when vegetation cover is minimal. This broader and more developed fracture zone suggests a higher degree of brecciation along TR2 relative to TR1. Alternatively, it could indicate a slight variation in subsurface lithology between the locations of TR1 and TR2 with parts of TR2 being underlain by comparatively more brittle rocks. As mentioned earlier, upon visual inspection of the site at TR2, we observed numerous rock boulders, some purely of quartz, as large as $0.6 \mathrm{~m}$ in diameter. An abundance of vein quartz or pegmatite intrusions could serve to weaken the subsurface crystalline bedrock and enable more intense fracturing. The multiple fractures could also suggest two successive regimes of deformation: a first regime, where the rocks fractured in a brittle manner likely creating thin joints which were later filled by quartzitic/or pegmatitic veins, and then a second regime which led to extensive brecciation of the rocks and veins, leaving behind visible boulders of quartz at the surface. The geoelectric response patterns of these "multiple fractures" indicate much lower resistivities than for the upstream end of the fracture system (along TR1). This possibly is a reflection of the higher degree of fracturing. Such a scenario would allow more fluids to migrate in the subsurface and thus lower rock resistivity.

"F1" is indicated as having been buried by recent sediments, while "F2" penetrates all the way to the near surface. This would suggest that the initiation of "F1" might have predated that of "F2" and that tectonic activity along "F1" might have ceased altogether and deformation transferred to "F2" [8]. Also, "F2" possibly channels more surface fluids from the stream course downward than "F1" as its low resistivity signature extends to the surface (in this case the stream location). At TR3 location, the geoelectric profile suggests that the fracture system has died out completely and ceased to control the stream course. We observed that in this area, the stream course is less linear. It meanders through the area and cuts deep grooves $(\sim 1.5 \mathrm{~m})$ into the surficial clayey topsoil. The depth limit of this fracture could not be determined from this study as it appears to transcend the maximum imaged depth along the geoelectric profiles.

The geoelectric profiles also indicate a set of basement trenches lying roughly parallel to the stream path/fracture system. These basement trenches vary from about $3 \mathrm{~m}$ depth (measuring from the maximum imaged height of the unweathered basement) to the north of the study area, specifically, along TR1, to approximately $7 \mathrm{~m}$ downstream at TR3. It is not known for certain if these trenches are structurally induced or controlled and whether they formed due to the same stress regime as the fractures or not. However, it is noted that they lie along the predominant geologic strike (N-S) in the area and parallel to the imaged fractures. We suggest that the trenches possibly developed as a result of tensile stress associated with the fracturing of the rocks. Alternatively, they may just represent weathering troughs whose preferential alignment has been encouraged by the dominant geologic strike and possible subsurface water migration trends [19]. It is noted that the locations of trenches particularly along TR1 and TR2 are capped by very low resistivity signatures, usually lower than $60 \mathrm{ohm}-\mathrm{m}$. These possibly represent very near-surface fluid migration regimes over these crystalline basements and may have been responsible for preferential local weathering of the basement and hence development of the trenches.

\section{Conclusion}

In this study, we have employed 2D electrical resistivity imaging to unravel the nature and propagation geometry of a suspected fracture system in Uneme-Nekhua, a linear settlement in the Basement complex region of the southwestern Nigeria. Our results indicate that the fracture system consists of multiple vertical fractures in the crystalline basement rocks of the area. The initiation of multiple fractures could possibly be adduced to the presence of massive vein quartz/or pegmatites. Our results further indicate that the stream path for most of its course is controlled by the imaged fracture system. The exception is far downstream where the fracture is observed to have died out totally. Our results also imaged a set of basement trenches running parallel to and east of the fracture system. We suggest that these trenches possibly originated due to tensile stresses which accompanied the formation of the imaged fractures.

\section{Conflict of Interests}

The authors declare that there is no conflict of interests regarding the publication of this paper.

\section{Acknowledgments}

The authors are very grateful to Mr. L. A. Akinola of the Department of Earth Sciences, Adekunle Ajasin University, Akungba Akoko, Nigeria, for cartographic support. 


\section{References}

[1] J. M. Reynolds, An Introduction to Applied and Environmental Geophysics, John Wiley \& Sons, West Sussex, UK, 1997.

[2] D. J. LaBrecque, A. L. Ramirez, W. D. Daily, A. M. Binley, and S. A. Schima, "ERT monitoring of environmental remediation processes," Measurement Science and Technology, vol. 7, no. 3, pp. 375-383, 1996.

[3] M. H. Loke, "Electrical imaging surveys for environmental and engineering studies: a practical guide to 2-D and 3-D surveys," 2000, http://www.heritagegeophysics.com/images/ lokenote.pdf.

[4] V. Frid, G. Liskevich, D. Doudkinski, and N. Korostishevsky, "Evaluation of landfill disposal boundary by means of electrical resistivity imaging," Environmental Geology, vol. 53, no. 7, pp. 1503-1508, 2008.

[5] J. T. Zume, A. Tarhule, and S. Christenson, "Subsurface imaging of an abandoned solid waste landfill site in Norman, Oklahoma," Ground Water Monitoring and Remediation, vol. 26, no. 2, pp. 62-69, 2006.

[6] E. Rizzo, A. Colella, V. Lapenna, and S. Piscitelli, "Highresolution images of the fault-controlled High Agri Valley basin (Southern Italy) with deep and shallow electrical resistivity tomographies," Physics and Chemistry of the Earth, vol. 29, no. 4-9, pp. 321-327, 2004.

[7] F. Nguyen, S. Garambois, D. Jongmans, E. Pirard, and M. H. Loke, "Image processing of $2 \mathrm{D}$ resistivity data for imaging faults," Journal of Applied Geophysics, vol. 57, no. 4, pp. 260-277, 2005.

[8] K. M. Bufford, E. A. Atekwana, M. G. Abdelsalam et al., "Geometry and faults tectonic activity of the Okavango Rift Zone, Botswana: evidence from magnetotelluric and electrical resistivity tomography imaging," Journal of African Earth Sciences, vol. 65, pp. 61-71, 2012.

[9] M. Moisidi, F. Vallianatos, P. Soupios, S. Kershaw, D. Rust, and S. Piscitelli, "Modelling tectonic features of the Kissamos and Paleohora areas, Western Crete (Greece): combining geological and geophysical surveys," Journal of Geophysics and Engineering, vol. 10, no. 2, Article ID 025015, 2013.

[10] G. El-Qady, M. Hafez, M. A. Abdalla, and K. Ushijima, "Imaging subsurface cavities using geoelectric tomography and groundpenetrating radar," Journal of Cave and Karst Studies, vol. 67, no. 3, pp. 174-181, 2005.

[11] I. A. Ololade, I. R. Ajayi, E. A. Gbadamosi, M. Z. Mohammed, and A. G. Sunday, "study of soil physico-chemical properties on Cocoa production in Ondo State," AModern Applied Science, vol. 4, no. 5, pp. 35-43, 2010.

[12] M. A. Rahaman, "Review of the Basement Geology of SouthWestern Nigeria," in Geology of Nigeria, C. A. Kogbe, Ed., pp. 39-56, Rock View, Abuja, Nigeria, 1989.

[13] A. I. Olayinka and M. O. Olorunfemi, "Determination of geoelectrical characteristics in Okene area and implication for boreholes sitting," Journal of Mining and Geology, vol. 28, pp. 403-412, 1992.

[14] M. E. Offodile, "The occurrence and exploitation of groundwater in Nigeria basement rocks," Journal of Mining and Geology, vol. 4, pp. 131-146, 1983.

[15] R. M. S. White, S. Collins, and M. H. Loke, "Resistivity and IP arrays, optimised for data collection and inversion," Exploration Geophysics, vol. 34, pp. 229-232, 2003.

[16] M. J. Yi and J. H. Kim, "Enhancing the resolving power of the least squares inversion with active constraint balancing," in
SEG Expanded Abstracts, 68 Annual Meeting, pp. 485-488, New Orleans, Fla, USA, 1998.

[17] W. M. Telford, L. P. Geldart, R. E. Sheriff, and D. A. Keys, Applied Geophysics, Cambridge University Press, Cambridge, UK, 2nd edition, 1990.

[18] O. Ritter, A. Hoffmann-Rothe, P. A. Bedrosian, U. Weckmann, and V. Haak, "Electrical conductivity images of active and fossil fault zones," in High-Strain Zones: Structure and Physical Properties, D. Bruhn and L. Burlini, Eds., Special Publications. v. 245, pp. 165-186, Geological Society of London, 2005.

[19] B. Robineau, J. L. Join, A. Beauvais, J.-C. Parisot, and C. Savin, "Geoelectrical imaging of a thick regolith developed on ultramafic rocks: groundwater influence," Australian Journal of Earth Sciences, vol. 54, no. 5, pp. 773-781, 2007. 

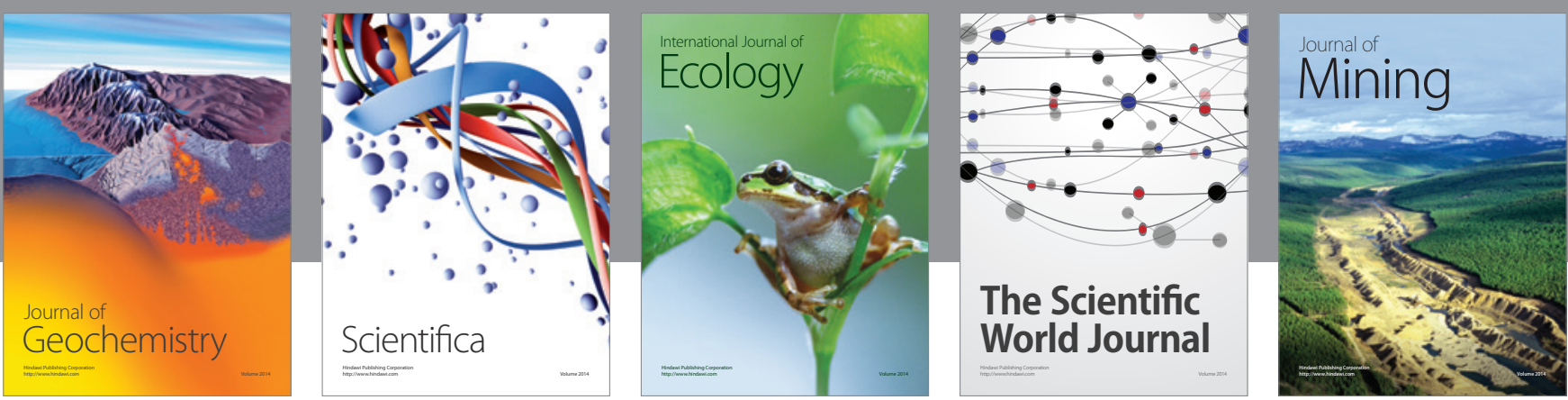

The Scientific World Journal
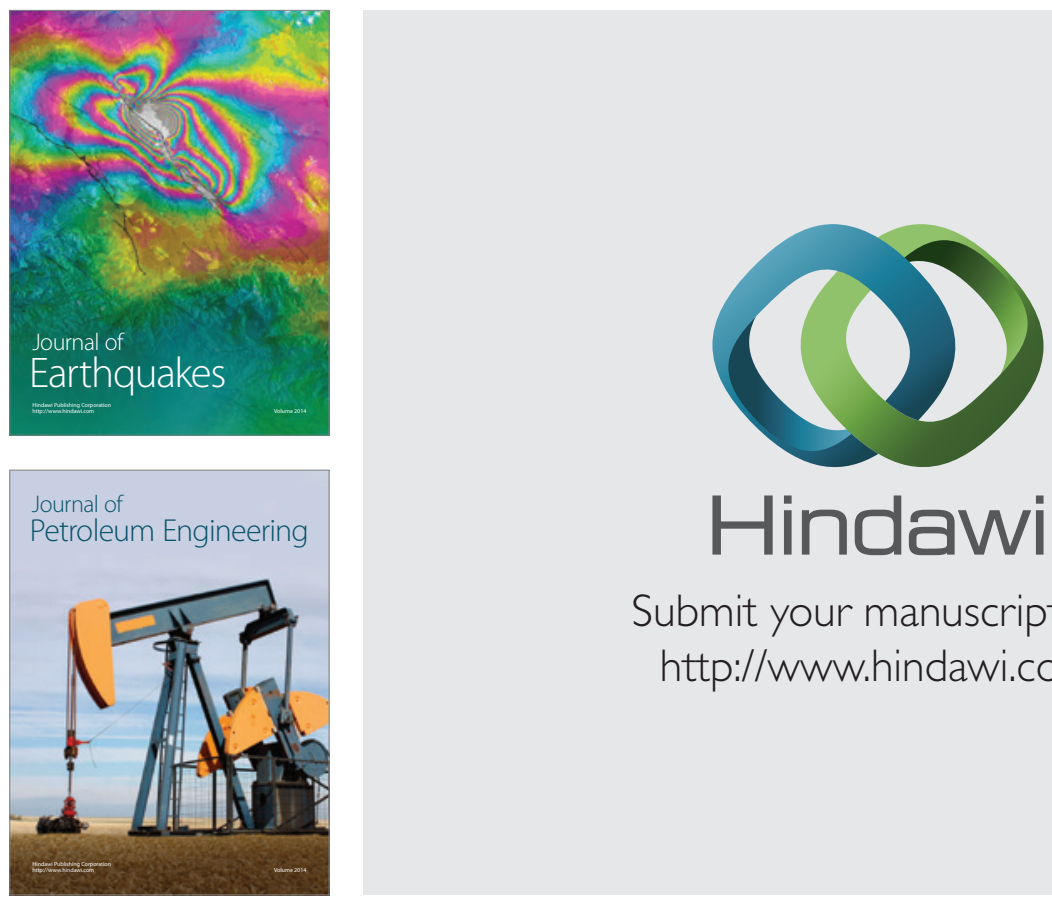

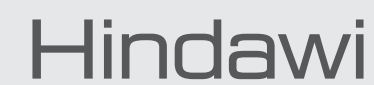

Submit your manuscripts at

http://www.hindawi.com
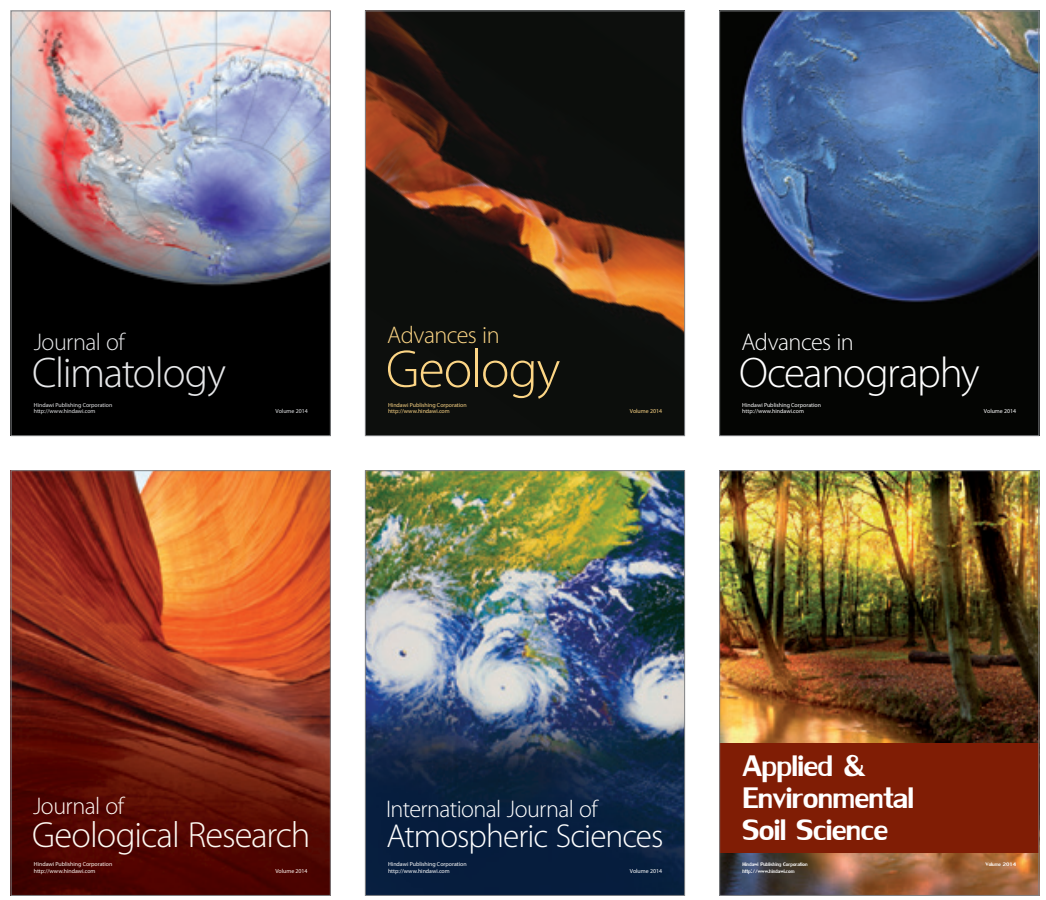
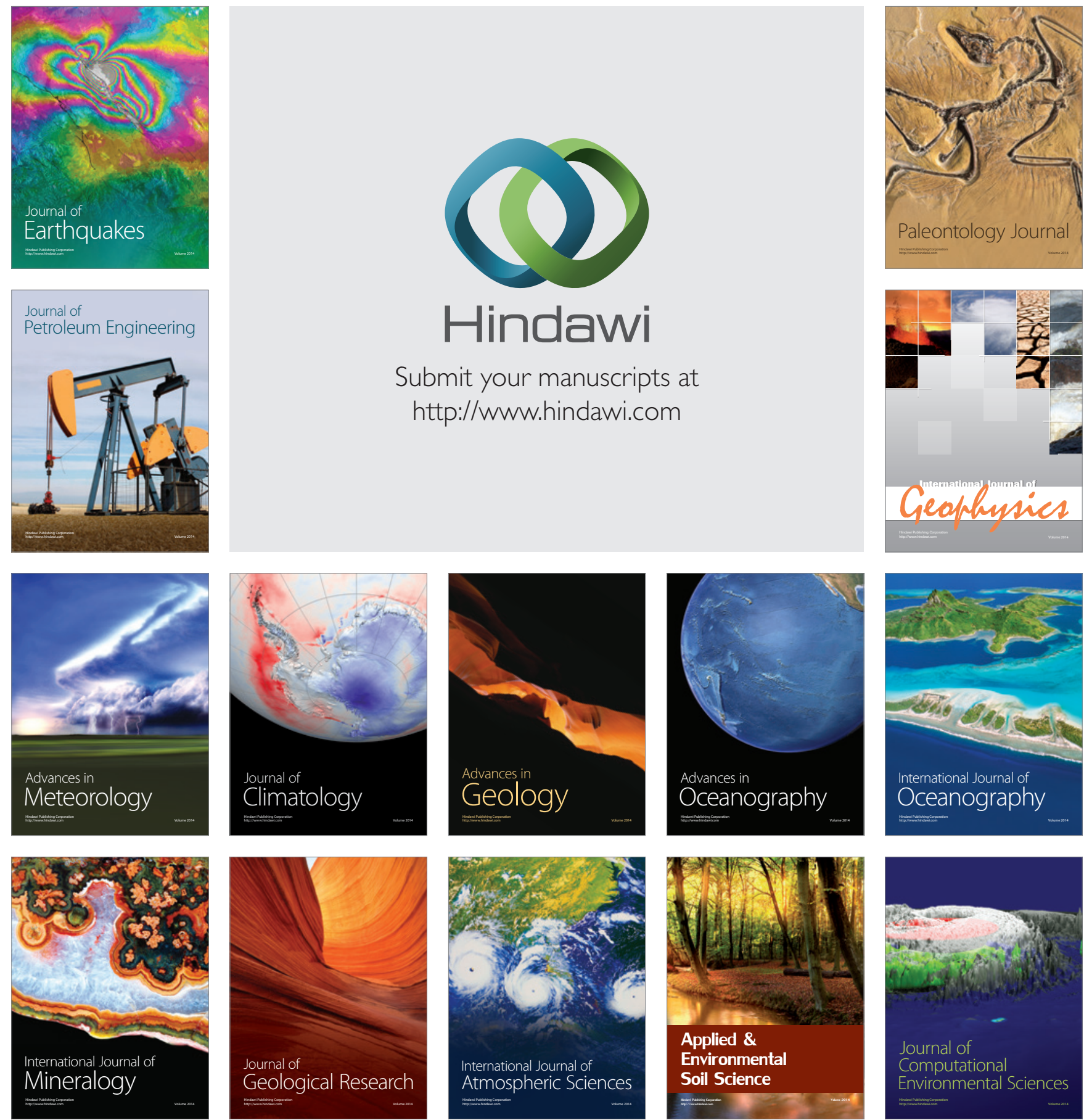